\title{
ESTUDO DA UTILIZAÇÃO DE SOLVENTE ALTERNATIVO NO PROCESSO DE EXTRAÇÃO DO ÓLEO DE SOJA
}

\author{
D. B. BAIÃO ${ }^{1}$, B. S. GARÉ ${ }^{1}$, A. C. M. RIBEIRO ${ }^{1}$, N. G. TROVÃO ${ }^{1}$, R. CONDOTTA ${ }^{1, *}$ \\ ${ }^{1}$ Centro Universitário FEI, Departamento de Engenharia Química \\ *E-mail: rcondotta@fei.edu.br
}

\begin{abstract}
RESUMO: A extração do óleo de soja é feita quase que exclusivamente pelo método de extração com hexano comercial. Com o intuito de avaliar novos solventes como alternativa deste processo tradicional de extração, foi realizado um estudo de extração do óleo de soja empregando-se misturas de etanol, acetato de etila e isopropanol como solvente. Como resultado, verificou-se que a mistura contendo $85 \%$ de etanol, $13 \%$ isopropanol e 2\% acetato de etila apresentou o melhor rendimento $(0,185 \mathrm{~g}$ óleo/g soja). Apesar do óleo bruto obtido apresentar índices de acidez e saponificação fora das especificações da ANVISA para óleo bruto, o refino deste óleo possibilitou a obtenção de um óleo refinado com algumas de suas propriedades próxima das exigidas pela ANVISA para óleos refinados, dentre elas o indice acidez: 0,7\% (exigido $<0,6 \%$ ). A inclusão da etapa de "winterization" no processo de refino pode contribuir com a melhoria das demais propriedades do óleo obtido pela extração com solvente alternativo.
\end{abstract}

PALAVRAS-CHAVE: Óleo de soja; Extração; Solvente; Refino.

\section{INTRODUÇÃO}

A industrialização de oleaginosas constitui-se num dos mais importantes setores do sistema agroindustrial, pela importância de seus produtos nas indústrias alimentícias, de cosméticos e como matéria-prima no processamento de alimentos para o consumo animal e humano (PARAISO, 2001).

Segundo levantamento feito pela USDA (United States Department of Agriculture) a safra mundial de soja 2014/2015 chegou a 318,6 milhões de toneladas. Em 2014 o Brasil possuía uma capacidade de processamento de óleos vegetais de 180,38 mil toneladas por dia, sendo que a produção de óleo de soja representa $30 \%$ do volume total.

De acordo com os dados apresentados pelo IBGE (Instituto Brasileiro de Geografia e Estatística), em dezembro de 2015 a área de soja a ser colhida teve um crescimento de 5,9\% quando comparado com o ano de 2014. Em números absolutos o incremento mais significativo entre as safras 2014/2015 ocorreu na produção de soja, que superou em 1 milhão de toneladas a safra de 2014 que era de 86,76 milhões (IBGE, 2015).

O cultivo da soja no Brasil se deu a partir da década de 60. No entanto, o grande 
avanço da produção ocorreu na década de 70 alavancado pela forte demanda internacional por soja em grãos e seus derivados, e pelo forte apoio governamental, em forma de subsídios. Sua industrialização coincidiu com a expansão da produção de grãos e iniciou-se nas pequenas empresas que se dedicavam ao processamento de outras oleaginosas tradicionais como o algodão e o amendoim.

O crescimento da demanda por produtos com maior valor agregado e a oportunidade de obtenção de maior volume com a exportação desses produtos tornou necessária grandes modificações na estrutura, no tamanho e nos processos de produção das empresas de processamento de soja no Brasil. A tecnologia de extração foi evoluindo através das décadas, e atualmente é possível obter óleos de alta qualidade pelo processo de extração por solvente, normalmente com hexano comercial.

A extração de óleo com solvente é feita num extrator, preferencialmente de forma contínua, do qual saem duas correntes importantes bem distintas. Uma é denominada de micela e a outra é denominada de torta. A micela é uma mistura líquida composta de óleo/solvente cujo teor de óleo está na faixa 24-30\% em massa; a torta por sua vez é uma mistura de farelo, solvente, água e uma pequena quantidade de óleo.

O hexano tem sido usado quase que exclusivamente na indústria devido a uma série de vantagens que ele apresenta, como alta estabilidade, capacidade de diluição do óleo com facilidade (sem atuar sobre os outros componentes), ser o mais eficiente em termos de consumo de energia e por apresentar o menor teor residual de óleo na torta (PARAÍSO, 2001).

Porém apresenta algumas desvantagens relevantes sob o ponto de vista ambiental e de segurança, como alta inflamabilidade e advir de fonte de origem não renovável (petróleo). Além disso, esse solvente não é puro, pois apresenta em sua composição uma mistura de diversos hidrocarbonetos com 6 carbonos em suas cadeias que provém dos resíduos do processo de refino do petróleo.

Os critérios para a escolha do solvente ideal a ser utilizado no processo de extração podem ser agrupados em classes. Sendo a classe de aceitabilidade do sistema a mais relevante em se tratando de extração sólido-líquido. E dentre os critérios, os que mais influem no processo e na operação são: corrosividade, pressão de vapor, inflamabilidade, recuperabilidade, custo e disponibilidade.

A legislação brasileira, por sua vez, vem tornando-se cada vez mais rigorosa quanto às tecnologias e processos utilizados na indústria de alimentos e estes processos devem garantir ao consumidor alimentos de qualidade e com os mais baixos níveis de resíduos possíveis. Assim, surge o objetivo principal deste trabalho que é um estudo para a substituição do hexano comercial, principal solvente na indústria de extração de soja, por uma mistura de etanol, acetato de etila e isopropanol que preserve a qualidade e a quantidade de óleo removida da matriz.

\section{MATERIAIS E MÉTODOS}

Os métodos utilizados neste trabalho estão divididos em (a) caracterização de matéria 
prima e do óleo extraído, operação de extração e refino. Todos eles são descritos a seguir com seus respectivos materiais (reagentes, equipamentos e vidrarias utilizados), sendo seguidos conforme normas ABNT (Associação Brasileira de Normas Técnicas), AOCS (American Oil Chemists' Society), Instituto Adolfo Lutz e notas de aula de Química Industrial II, cedidas pelo Prof. Dr. Luiz Fernando Peffi Ferreira.

\subsection{Caracterização da matéria prima}

Primeiramente, a soja com casca in natura foi seca em estufa por 6 horas a $60^{\circ} \mathrm{C}$, pois a umidade excessiva permite o desenvolvimento de fungos e propicia a atividade enzimática (GAUTO, 2013). Em seguida foi processada em triturador doméstico a fim de aumentar a superfície de contato, armazenada em sacos de vedação e conservada em local fresco e seco, ao abrigo da luz.

Teor de cascas: Industrialmente, as sementes de soja sofrem um processo de descasque antes de seguirem para a extração, pois as cascas possuem menor conteúdo de óleo e proteína. Porém, o processo de extração foi realizado com as sojas trituradas com casca. Para se obter uma comparação com o processo de extração industrial, o teor mássico da casca deveria ser quantificado. Para tanto, uma certa quantia de soja seca, não triturada, foi pesada, retirada manualmente suas cascas e pesado novamente o conteúdo sem casca.

Análise granulométrica: A análise granulométrica consistiu no peneiramento de uma amostra de soja triturada de massa conhecida em peneiras, segundo a série Tyler 4, 8, 14, 28, 35, 65, 100, 150 e 200, durante 60 minutos. Este teste foi feito em duplicata.

\subsection{Extração do óleo de soja}

As extrações foram conduzidas em extrator Soxhlet acoplado a um condensador de refluxo e a um balão de vidro redondo de 0,5 litros de 3 bocas, sendo uma delas conectada a um termômetro, uma ao extrator e a terceira tampada. Ao balão foi adicionado 0,325 L do solvente a ser estudado no processo de extração e então aquecido através de manta elétrica. $\mathrm{O}$ extrator (Soxhlet) foi carregado com sementes de soja trituradas com cascas em um cartucho de extração de $0,1 \mathrm{~m}$ de altura, com massa previamente pesada. $\mathrm{O}$ processo foi conduzido durante 3 horas a partir da visualização do primeiro refluxo de solvente, segundo o processo otimizado descrito por Novazzi e Hipólito, 2012.

O solvente empregado no processo de extração consistiu de uma mistura de etanol, acetato de etila e isopropanol, cuja composição foi obtida por um planejamento de experimentos do tipo fatorial $2^{2}+1$, apresentado na seção 2.4 .

No intuito de se comparar as características do óleo de soja obtido a partir das diferentes composições do solvente alternativo e do óleo de soja tradicionalmente empregando-se o hexano com solvente, realizou-se também a extração com hexano no mesmo sistema laboratorial, de forma a considerar os efeitos devido à redução de escala e demais variáveis do processo em escala laboratorial.

As extrações com hexano e com as misturas de solventes foram conduzidas em mais de um conjunto experimental de extração, a fim de se obter a quantidade de óleo necessária para 
realizar os testes de caracterização. Foram realizadas três bateladas de extrações diferentes: uma primeira batelada de extrações com hexano; uma segunda batelada de extrações com as misturas de solvente, e uma terceira batelada, que consistiu na duplicata da segunda batelada, exceto pelo fato de que a mistura 3 (ponto central) foi realizada duas vezes nesta batelada. A Tabela 1 apresenta os conjuntos experimentais para cada condição de extração.

Tabela 1 - Conjuntos experimentais das extrações.

\begin{tabular}{cccccc}
\hline $\begin{array}{c}\text { Solvente/ } \\
\text { mistura }\end{array}$ & $\begin{array}{c}\text { Temperatura } \\
\left({ }^{\circ} \mathbf{C}\right)\end{array}$ & $\begin{array}{c}\text { Número de } \\
\text { Sohxlets }\end{array}$ & $\begin{array}{c}\text { Altura de } \\
\text { massa de soja }(\mathbf{c m})\end{array}$ & $\begin{array}{c}\text { Volume de solvente } \\
\text { por Soxhlet }(\mathbf{m L})\end{array}$ & $\begin{array}{c}\text { Número de } \\
\text { bateladas }\end{array}$ \\
\hline Hexano & 65,00 & 8 & 10 & 325 & 1 \\
1 & 75,05 & 3 & 10 & 325 & 2 \\
2 & 76,00 & 3 & 10 & 325 & 2 \\
3 & 76,00 & 3 & 10 & 325 & 2 \\
4 & 76,00 & 3 & 10 & 325 & 2 \\
5 & 76,00 & 3 & 10 & 325 & 2 \\
\hline
\end{tabular}

Após a realização das extrações, o conteúdo do balão de vidro foi submetido ao processo de destilação para a remoção do solvente nele contido. Foram realizadas duas destilações, uma simples e uma a vácuo.

A micela extraída com hexano foi destilada após seu resfriamento. As micelas da primeira batelada extraídas com as misturas de solventes foram resfriadas. Este resfriamento resultou na formação de um resíduo de fundo, o qual foi e removido antes da destilação. Já as destilações da segunda batelada foram realizadas logo após as extrações, com as micelas ainda quentes e com o resíduo em suspensão. Assim, a extração da segunda batelada foi mais fiel ao processo industrial, onde a remoção do solvente do óleo ocorre à quente, o que possibilitou avaliar a influência do resíduo no teste de qualidade.

\subsection{Caracterização do óleo extraído}

Os óleos extraídos foram caracterizados pelas análises de índice de acidez (IA), índice de saponificação (IS) e umidade (\%U), e pelo rendimento mássico do processo. Todas as análises analíticas foram realizadas em duplicata, salvo as amostras que não possuíam quantidade suficiente de óleo.

Determinação da Acidez: O índice de acidez é definido como o número de miligramas de hidróxido de potássio necessário para neutralizar um grama da amostra. Esta análise fornece um dado importante sobre o estado de conservação do óleo, uma vez que a decomposição, seja por hidrólise, oxidação ou fermentação, modifica a concentração dos íons hidrogênio (INSTITUTO ADOLFO LUTZ, 1985). A análise foi realizada segundo método ABNT NBR 11115:2014.

Determinação do Índice de Saponificação: O índice de saponificação (IS) representa a quantidade de álcali necessário para saponificar os ácidos graxos presentes na amostra de óleo, e expressa a quantidade em miligramas de hidróxido de potássio necessário para saponificar um grama de amostra. Através da reação de saponificação é possível estabelecer a estabilidade e grau de conservação do óleo (INSTITUTO ADOLFO LUTZ, 1985). O procedimento foi realizado segundo método AOCS Cd 3-25 (AOCS, 1990). 
Determinação da Umidade e Matéria Volátil: A determinação da umidade e matéria volátil é um dos parâmetros legais para a avaliação da qualidade de óleos e gorduras, sendo realizada por aquecimento direto. O procedimento foi feito segundo método 334/IV do Instituto Adolfo Lutz (1985).

\subsection{Planejamento estatístico dos experimentos}

As variáveis independentes ou preditoras de níveis previamente fixados são fatores e podem ser analisadas por esquemas fatoriais que envolvem combinações entre os níveis de dois ou mais fatores. O estudo de sistemas multivariados se dá por meio de uma técnica denominada planejamento estatístico, um arranjo ortogonal que descreve o espaço experimental escolhido de modo confiável, no qual se consegue variar simultaneamente as variáveis eleitas como independentes, de tal forma que os efeitos mensurados dessas variáveis e de suas interações, numa dada variável dependente, sejam matematicamente independentes além de permitir ajustar os polinômios ortogonais que são necessários para otimizar as variáveis independentes (ALMEIDA et al., 2014, p.35).

Neste trabalho, as frações mássicas de etanol, acetato de etila e isopropanol são variáveis não ortogonais, não sendo possível mantê-las independentes entre si e ao mesmo tempo respeitar a condição do balanço de massa no qual o somatório das frações mássicas de todos os componentes da mistura é igual a 100\% da composição.

Ao expressar uma das variáveis composicional como razão das frações mássicas entre dois componentes não utilizados em outra variável composicional e mantendo-se a composição global da mistura constante, as frações mássicas de todos os constituintes formam transformadas em variáveis independentes.

Assim, para a realização deste trabalho, foi proposto um modelo experimental fatorial do tipo $2^{2}+1$ (duas variáveis independentes com dois níveis cada mais um ponto central), totalizando 11 experimentos. As variáveis independentes propostas foram (R1) a fração mássica de etanol (EtOH) e (R2) a razão entre a fração mássica de acetato de etila e a fração mássica de isopropanol, (AcOEt/Isop), de forma que a soma desses fatores seja 1. A Tabela 2 apresenta as variáveis independentes em valores absolutos e na forma de variáveis codificadas.

Tabela 2 - Fração mássica da mistura e variáveis independentes.

\begin{tabular}{cccccccc}
\hline \multirow{2}{*}{ Mistura } & \multicolumn{3}{c}{ Fração mássica } & \multicolumn{3}{c}{ Variáveis independentes } \\
\cline { 2 - 7 } & Etanol & Acetato de Etila & Isopropanol & R1 & R2 & R1 & R2 \\
\hline 1 & 0,850 & 0,020 & 0,130 & 0,850 & 0,150 & +1 & -1 \\
2 & 0,850 & 0,050 & 0,100 & 0,850 & 0,500 & +1 & +1 \\
3 & 0,675 & 0,080 & 0,245 & 0,675 & 0,320 & 0 & 0 \\
4 & 0,500 & 0,167 & 0,333 & 0,500 & 0,500 & -1 & +1 \\
5 & 0,500 & 0,065 & 0,435 & 0,500 & 0,150 & -1 & -1 \\
\hline
\end{tabular}

Com esse tipo de planejamento é possível determinar os efeitos principais e de interação que as variáveis independentes produzem nas respostas. Desta forma, o índice de saponificação (IS), o índice de acidez (IA) e o rendimento do processo (R) foram definidos 
como as variáveis dependentes (respostas) e os efeitos de cada variável independente e suas possíveis interações foram avaliados a partir da análise dos coeficientes dos polinômios ortogonais ajustados. O nível de significância de cada coeficiente polinomial foi calculado ( $p$-level) e comparado com o valor de significância pré-fixado de 0,05 , usando o teste de hipótese de $t$-student.

Os coeficientes do polinômio ortogonal $\beta_{0}, \beta_{1}, \beta_{2}, \beta_{12}$ e seus respectivos erros padrão (EP) são determinados através do processamento dos dados experimentais, no módulo de regressão múltipla, usando o software Statistica ${ }^{\circledR}$ (v.12), o qual fornece uma forma genérica segundo a Equação 1, para cada variável resposta, onde o sub-índice $j$ identifica a variável de resposta.

$y_{i}=\beta_{0_{j}}+\beta_{1_{j}} R_{1}+\beta_{2_{j}} R_{2}+\beta_{12_{j}} R_{1} R_{2}$

\subsection{Refino do óleo extraído}

Após identificado qual das misturas alternativas de solventes resultou na extração de óleo de soja com as melhores condições, uma nova batelada desta "melhor" extração foi realizada e o produto obtido submetido ao processo de refino, no intuito de se verificar se o mesmo se enquadrava nas normas da ANVISA para óleos refinados.

Com o intuito de avaliar a influência do resíduo formado durante o processo de extração do óleo de soja com a mistura de solvente alternativo, os produtos de todas as bateladas anteriores foram resfriados para favorecer a decantação do resíduo. Após a remoção destes resíduos, todos os óleos foram homogeneizados e submetidos ao processo de refino.

As etapas do procedimento empregado para o refino dos óleos extraídos são descritas a seguir, sendo que ao término de cada etapa, a massa de óleo processada era medida a fim de se determinar a massa removida em cada procedimento.

Degomagem: Pesou-se uma massa de óleo de soja bruto aquecendo-a até aproximadamente 50 a $60^{\circ} \mathrm{C}$. Adicionou-se $3 \%$ de $\mathrm{NaCl}$ em solução aquosa a $10 \%$ em massa e manteve-se essa condição por 90 minutos. Feito isso, transferiu-se a mistura para um funil de decantação onde permaneceu em repouso de um dia para o outro. Extraiu-se e descartouse a fase aquosa, reservando a fase óleo.

Neutralização: A fase óleo obtida na degomagem foi aquecida entre 50 e $60^{\circ} \mathrm{C}$ e adicionou-se a quantidade necessária (obtida através do índice de acidez) de solução aquosa de $\mathrm{NaOH} \mathrm{10 \%} \mathrm{em} \mathrm{massa,} \mathrm{agitou-se} \mathrm{lentamente} \mathrm{e} \mathrm{manteve-se} \mathrm{essa} \mathrm{condição} \mathrm{por} 90$ minutos. Transferiu-se a mistura para um balão de decantação onde foi deixada de um dia para o outro, separando-se posteriormente o sabão formado.

Lavagem: A lavagem foi feita em duas etapas em um funil de separação. Na primeira etapa a lavagem foi feita com água a $85^{\circ} \mathrm{C}$ sem agitação, adicionando-se um volume de água aproximadamente igual ao volume de óleo, separando-se a fase aquosa do óleo após cada lavagem, o procedimento foi repetido por quatro vezes. A segunda etapa da lavagem foi feita de modo semelhante à primeira etapa, mas com água entre 90 e $95^{\circ} \mathrm{C}$ sob agitação lenta até 
que a fase aquosa saísse límpida. Após a lavagem o óleo foi seco por destilação a vácuo.

Branqueamento: $\mathrm{O}$ óleo seco foi pesado e aquecido a $120^{\circ} \mathrm{C}$ sob agitação branda, adicionou-se $1,5 \%$ em massa de carvão ativado e a temperatura foi controlada entre $110 \mathrm{e}$ $120^{\circ} \mathrm{C}$ por 30 minutos. $\mathrm{O}$ carvão foi removido por filtração a vácuo.

Desodorização: O óleo branqueado foi destilado com arraste a vapor. Após essa operação o óleo foi seco por destilação a vácuo e determinou-se a massa de óleo refinado.

\section{RESULTADOS E DISCUSSÕES}

Neste tópico são apresentados os resultados referentes à caracterização da matéria prima, os resultados das extrações com hexano e com as misturas de diferentes frações mássicas de solventes; os resultados dos testes de caracterização dos óleos obtidos; a análise estatística de experimentos que permitiu identificar o melhor processo de extração e, por fim, os resultados dos testes de caracterização dos óleos submetidos ao processo de refino.

\subsection{Caracterização da Matéria Prima}

A porcentagem mássica de cascas nos grãos de soja foi estimada em torno de $8,36 \%$ e este valor deve ser considerados nos cálculos para efeito de comparação com o processo industrial, o qual utiliza a soja sem casca. Os parâmetros da análise granulométrica realizadas estão apresentados na Tabela 3.

Tabela 3 - Diâmetro médio das partículas de soja, média dos resultados.

\begin{tabular}{ccc}
\hline Diâmetro & Média $(\mathbf{m m})$ & Erro $(\mathbf{m m})$ \\
\hline Médio aritmético & 0,39278 & 0,01084 \\
Médio superficial & 0,10214 & 0,00928 \\
Médio volumétrico & 0,01871 & 0,00334 \\
\hline
\end{tabular}

\subsection{Extração do óleo de soja}

Considerando o rendimento mássico e termos de grama de óleo com resíduo obtido por grama de soja com casca utilizada, os valores médios dos rendimentos da primeira e da segunda batelada de cada mistura são apresentados nas Tabelas 4 e na Figura 1.

Tabela 4 - Rendimento das extrações após destilação.

\begin{tabular}{ccccccc}
\hline Extração & MO+R (g) & $\begin{array}{c}\text { Desvio } \\
\text { padrão }(\mathbf{g})\end{array}$ & Resíduo (g) & \% Resíduo (\%) & MO-R (g) & \% óleo (\%) \\
\hline Hexano & 93,106 & - & 0,000 & - & 93,106 & - \\
1 & 48,420 & 22,487 & 27,979 & 57,785 & 20,441 & 42,215 \\
2 & 35,651 & 12,019 & 16,795 & 47,108 & 18,857 & 52,892 \\
3 & 47,255 & 12,934 & 19,564 & 41,401 & 27,691 & 58,599 \\
4 & 37,402 & 20,589 & 5,795 & 15,495 & 31,606 & 84,505 \\
5 & 41,620 & 11,724 & 8,030 & 19,461 & 33,231 & 80,539 \\
\hline \multicolumn{7}{l}{ Legenda - MO+R: massa de óleo + resíduo; MO-R: massa de óleo - resíduo } \\
\hline
\end{tabular}




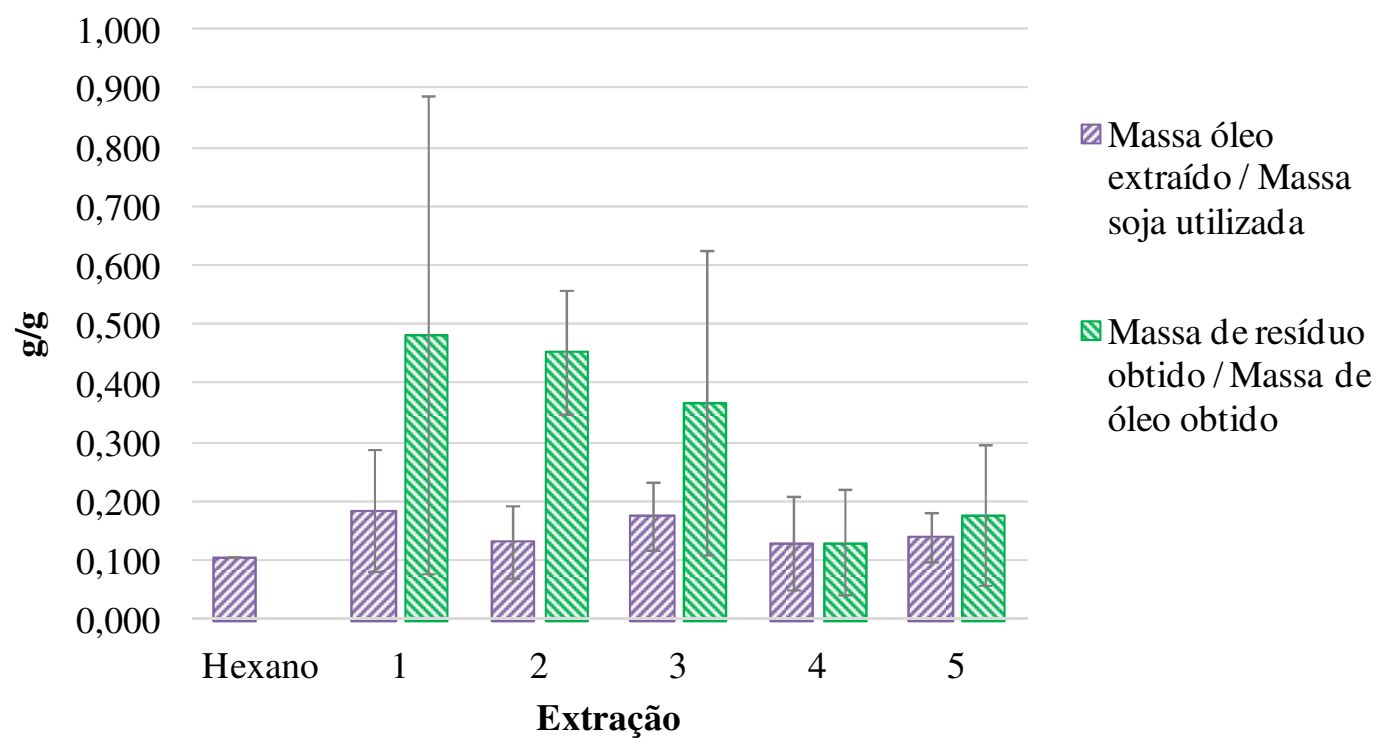

Figura 1 - Rendimento das extrações.

Os altos valores de desvio padrão são justificados pela diferença no processo de destilação entre as bateladas (as micelas da primeira batelada foram resfriadas e destiladas na ausência de resíduo e as micelas da segunda batelada, quente e com resíduo). Após a separação do solvente e resfriamento dos óleos de ambas as bateladas, observou-se a precipitação de resíduo.

$\mathrm{O}$ rendimento do processo de extração com hexano foi de $0,107 \mathrm{~g}$ de óleo/g de soja. $\mathrm{O}$ rendimento abaixo do reportado por Rodrigues (2011) de 0,170 g de óleo/g de soja, se deve ao fato de que o sistema de extração em escala de bancada não é tão eficiente quanto o utilizado industrialmente e pela soja ter sido utilizada com cascas. Desta forma, este será foi considerado como o máximo rendimento possível segundo as condições e equipamentos empregados neste trabalho.

Ao comparar os rendimentos das extrações, observa-se que os rendimentos de todas as extrações realizadas com as misturas de solventes ultrapassaram o valor do rendimento da extração com hexano. Isto ocorreu porque a utilização dessa nova mistura de solventes resultou na precipitação de um resíduo, após o resfriamento, não existente quando se emprega hexano. Provavelmente, deve ter ocorrido o arraste de substâncias que possuem afinidade com o etanol e/ou acetato de etila e/ou isopropanol. A batelada adicional realizada para o refino do óleo apresentou um rendimento de $0,115 \mathrm{~g}$ óleo/g soja.

\subsection{Características dos Óleos Obtidos}

Como pode ser observado na Figura 2, o óleo extraído com o hexano apresenta um índice de acidez de 1,8\% ácido oleico; é um óleo em bom estado de conservação estando dentro da norma ANVISA ( $<2,0 \%$ ácido oleico), assim os íons hidrogênio não foram significativamente alterados por decomposição.

Já os demais óleos apresentam índice de acidez maior que o estabelecido pela norma, devido ao fato de que os solventes utilizados na preparação das misturas arrastam água 
durante a extração, ocasionando a hidrólise dos triacilgliceróis, formando ácidos graxos livres, o que acarreta na degradação do óleo aumentando seu índice de acidez.

O óleo extraído com a mistura 1 foi o que apresentou o maior índice de acidez (7,6\% ácido oleico) e consequentemente, foi o óleo que mais sofreu hidrólise, seguido do óleo extraído com a mistura 5 (5,5\% ácido oleico) e do óleo extraído com a mistura 2 (5,1\% ácido oleico). Em geral, o valor médio do índice de acidez para todas as extrações ficou em torno de $5 \%$.

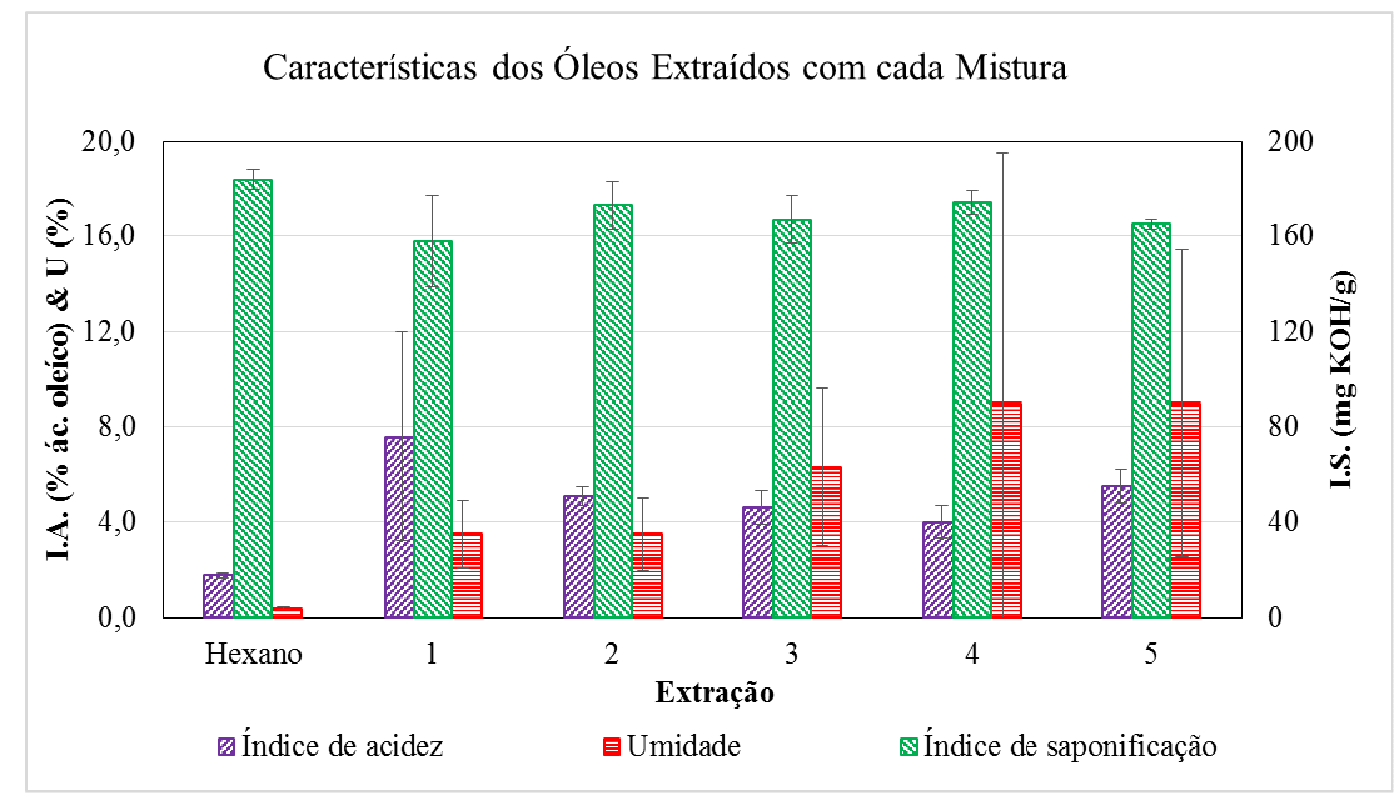

Figura 2 - Características dos óleos extraídos.

Todos os óleos extraídos apresentaram índice de saponificação abaixo da faixa estabelecida pela legislação: 189-195 mg KOH/g. O óleo extraído com hexano apresentou índice de saponificação de $184 \mathrm{mg} \mathrm{KOH/g} \mathrm{e} \mathrm{os} \mathrm{óleos} \mathrm{extraídos} \mathrm{com} \mathrm{as} \mathrm{misturas} \mathrm{de} \mathrm{solventes}$ apresentaram um índice de saponificação médio de aproximadamente $166 \mathrm{mg} \mathrm{KOH} / \mathrm{g}$. Dentre estes, óleo da mistura 1 apresentou menor índice de saponificação (158 mg KOH/g), seguido do óleo extraído com a mistura $5(165 \mathrm{mg} \mathrm{KOH} / \mathrm{g})$ e do óleo extraído com a mistura 3 (167 mg KOH/g).

O baixo índice de saponificação está diretamente relacionado com o alto índice de acidez, pois no processo de hidrólise são formados ácidos graxos que em meio básico saponificam, formando sabão e glicerol.

O fato dos os óleos extraídos com as misturas de solventes apresentarem um índice de saponificação inferior ao estabelecido pela ANVISA já era esperado, visto que esta característica está relacionada com o grupo hidroxila do etanol e do isopropanol usado na extração, uma vez que este grupo funcional deixa o meio com carácter básico, ocorrendo assim, a hidrólise e a saponificação do óleo. Como o índice de saponificação é a quantidade de base necessária para saponificar o óleo e muitas moléculas já foram parcialmente saponificadas durante a extração, a quantidade de base necessária para saponificar as moléculas de ácidos graxos remanescente é reduzida. 
O valor do índice de acidez do óleo extraído com o hexano também ficou abaixo do valor limite estabelecido pela norma da ANVISA, porém mais próximo do limite que o das misturas. A destilação da micela após seu resfriamento e as demais variações entre o processo de extração utilizado em escada de bancada e o processo industrial devem ter contribuído para que isso ocorresse.

Em relação a porcentagem de umidade e matéria volátil, o óleo extraído com hexano atendeu à norma da ANVISA, uma vez que não apresentou resíduos significativos de solvente e não houve o arraste de umidade no processo de extração, ao contrário dos óleos extraídos com as misturas, que tiveram umidade e matéria volátil acima do estabelecido pela norma. O valor médio de umidade de matéria volátil para todas as misturas ficou em torno de $4 \%$, onde o maior teor $(9,0 \%)$ foi observado nas misturas 4 e 5.

Os erros de cada batelada e o desvio padrão entre as bateladas são significativos, o que se deve principalmente à falta de reprodutibilidade no processo de remoção dos solventes do óleo por destilação: taxa de destilação, temperatura de destilação, que é função do ponto de ebulição nas misturas com diferentes composições.

\subsection{Análise Estatística das Condições de Extração}

Os resultados das características dos óleos obtidos nas duas bateladas de extração, totalizando 11 extrações, foram analisados estatisticamente com o auxílio do software Statistica ${ }^{\circledR}$ (v.12). Estes foram alimentados como variáveis dependentes no planejamento experimental para o estudo da influência das variáveis independentes R1 e R2 (fração mássica de etanol e relação AcOEt/Isop, respectivamente) nos processos de extração. A Tabela 5 apresenta a matriz do planejamento e as correspondentes variáveis respostas médias.

Os resultados dos modelos ajustados para o índice de acidez, índice de saponificação e rendimentos obtidos pelo software Statistica®, são apresentados na Tabela 6.

Tabela 5 - Dados para o Planejamento Experimental.

\begin{tabular}{|c|c|c|c|c|c|}
\hline \multirow{2}{*}{ Batelada } & \multicolumn{2}{|c|}{ Variáveis codificadas } & \multicolumn{3}{|c|}{ Variáveis respostas } \\
\hline & R1 & $\mathbf{R 2}$ & IA (\% ácido oléico) & IS (mgкон/g) & R (góleo/gsoja) \\
\hline \multirow{5}{*}{ Primeira } & +1 & -1 & 4,4 & 171 & 0,111 \\
\hline & +1 & +1 & 5,3 & 166 & 0,090 \\
\hline & 0 & 0 & 5,3 & 170 & 0,116 \\
\hline & -1 & -1 & 3,5 & 177 & 0,074 \\
\hline & -1 & -1 & 6,0 & 164 & 0,112 \\
\hline \multirow{6}{*}{ Segunda } & +1 & -1 & 10,7 & 145 & 0,259 \\
\hline & +1 & +1 & 4,8 & 180 & 0,174 \\
\hline & 0 & 0 & 3,8 & 156 & 0,181 \\
\hline & 0 & 0 & 4,7 & 175 & 0,229 \\
\hline & -1 & +1 & 4,5 & 170 & 0,186 \\
\hline & -1 & -1 & 5,0 & 166 & 0,171 \\
\hline
\end{tabular}


Tabela 6 - Modelo ajustado para o índice de acidez, saponificação e rendimento.

\begin{tabular}{|c|c|c|c|c|}
\hline \multicolumn{5}{|c|}{ Índice de acidez $\left(R^{2}=0,39413580\right)$} \\
\hline $\mathrm{N}=\mathbf{2 0}$ & $\beta$ & Std. Err. of $\beta$ & $\mathbf{t}(\mathbf{1 6})$ & p-level \\
\hline Intercept & 5,3849 & 0,3681 & 14,6566 & 0,0000 \\
\hline R1 & 0,8117 & 0,4115 & 1,9724 & 0,0661 \\
\hline R2 & $-1,0274$ & 0,4115 & $-2,4967$ & 0,0238 \\
\hline $\mathbf{R} 1 \cdot \mathbf{R} 2$ & $-0,2197$ & 0,4115 & $-0,5338$ & 0,6008 \\
\hline \multicolumn{5}{|c|}{ Índice de saponificação $(\mathrm{R} 2=0,36919403)$} \\
\hline $\mathbf{N}=\mathbf{2 0}$ & $\beta$ & Std. Err. of $\beta$ & $\mathbf{t}(\mathbf{1 6})$ & p-level \\
\hline Intercept & 168,4789 & 1,8740 & 86,9056 & 0,0000 \\
\hline R1 & $-1,8368$ & 2,0951 & $-0,8767$ & 0,3936 \\
\hline R2 & 5,9588 & 2,0951 & 2,8441 & 0,0117 \\
\hline $\mathbf{R} 1 \cdot \mathbf{R} 2$ & 1,4916 & 2,0951 & 0,7119 & 0,4868 \\
\hline \multicolumn{5}{|c|}{ Rendimento: $1^{\mathrm{a}}$ batelada $\left(\mathrm{R}^{2}=\mathbf{0 , 7 8 5 6 4 3 4 0 )}\right.$} \\
\hline$N=5$ & $\beta$ & Std. Err. of $\beta$ & $\mathbf{t}(\mathbf{1})$ & p-level \\
\hline Intercept & 0,1016 & 0,0072 & 14,1111 & 0,0450 \\
\hline R1 & 0,0050 & 0,0081 & 0,6211 & 0,6462 \\
\hline R2 & $-0,0135$ & 0,0081 & $-1,6771$ & 0,3423 \\
\hline $\mathbf{R 1} \cdot \mathbf{R 2}$ & 0,0055 & 0,0081 & 0,6832 & 0,6184 \\
\hline \multicolumn{5}{|c|}{ Rendimento: $\mathbf{2}^{\mathrm{a}}$ batelada $\left(\mathbf{R}^{2}=\mathbf{0}, \mathbf{8 0 8 1 6 1 3 5}\right)$} \\
\hline$N=6$ & $\beta$ & Std. Err. of $\beta$ & $\mathbf{t}(2)$ & p-level \\
\hline Intercept & 0,2000 & 0,0101 & 19,7787 & 0,0025 \\
\hline R1 & 0,0190 & 0,0124 & 1,5342 & 0,2647 \\
\hline R2 & $-0,0175$ & 0,0124 & $-1,4131$ & 0,2932 \\
\hline $\mathbf{R} 1 \cdot \mathbf{R 2}$ & $-0,0250$ & 0,0124 & $-2,0187$ & 0,1810 \\
\hline
\end{tabular}

Onde o Std. Err.of $\beta$ é o erro padrão de cada coeficiente; o t é o teste $t$-student com seu respectivo grau de liberdade; o p-level é o nível de significância (o qual foi fixado em 5\% para o planejamento proposto); o Intercept é o valor médio de todos os valores medidos experimentalmente e o R2 é o coeficiente de correlação múltiplo.

Observa-se que os valores obtidos dos coeficientes de correlação múltiplo para o índice de acidez (IA) e para o índice de saponificação, para o planejamento experimento proposto, foram de $\mathrm{R}^{2}=0,3941$ e $\mathrm{R}^{2}=0,3692$, respectivamente, empregando-se todos os 11 valores médios destes parâmetros.

Como os valores do rendimento da primeira e da segunda batelada são discrepantes pelo fato dos óleos extraídos na primeira batelada terem sido separados do solvente por destilação na ausência de seus resíduos e os óleos da segunda batelada terem sido destilados com o resíduo, os rendimentos das bateladas são avaliados separadamente. A análise separada das dos rendimentos permitiu a obtenção de coeficientes de correlação superiores: $\mathrm{R}^{2}=0,7856$ para o rendimento da primeira batelada e $\mathrm{R}^{2}=0,8082$ para o rendimento da segunda batelada.

Os índices de acidez e saponificação não foram influenciados pela alteração na operação de destilação, uma vez que os resultados das propriedades dos óleos das diferentes bateladas foram próximos, exceto pela mistura 1, permitindo a análise de superfície dos valores médios entre as bateladas.

Observa-se a partir dos valores de $p$-level na Tabela 5 que somente a variável R2 (razão AcOEt/Isop) é estatisticamente significante para os índices de acidez (IA) e de saponificação 
(IS), porém de maneira inversa: o aumento da quantidade de acetato de etila resulta num aumento do índice de saponificação e na diminuição do índice de acidez, mas este comportamento invertido é coerente, conforme explicado anteriormente

Já para o rendimento das bateladas, os dados da Tabela 5 demonstram que nenhuma das variáveis independentes é estatisticamente significante, segundo o planejado experimentalmente proposto. Neste caso, pode-se afirmar que o refino de óleo de soja empregando a mistura alternativa de solvente apresente um rendimento de $10 \%$ quando o resíduo é separado do óleo antes do processo de destilação, e de $20 \%$ quando todo o produto da extração é submetido a etapa de destilação.

As Figuras 3, 4, 5 e 6 são os gráficos de superfícies para o índice de acidez, índice de saponificação e rendimento da primeira e segunda batelada.

Finalmente, ao se fazer uma análise das superfícies de respostas apresentada pelas Figuras 5 e 6, é possível identificar visualmente que, em ambas as bateladas, o aumento da fração de etanol sob baixa a relação AcOEt/Isop tende a aumentar o rendimento das extrações. Entretanto, tal comportamento não pode ser constatado através de uma análise estatística pelo fato de cada batelada ser conduzida de maneira diferente e fornecer apenas um valor de rendimento.

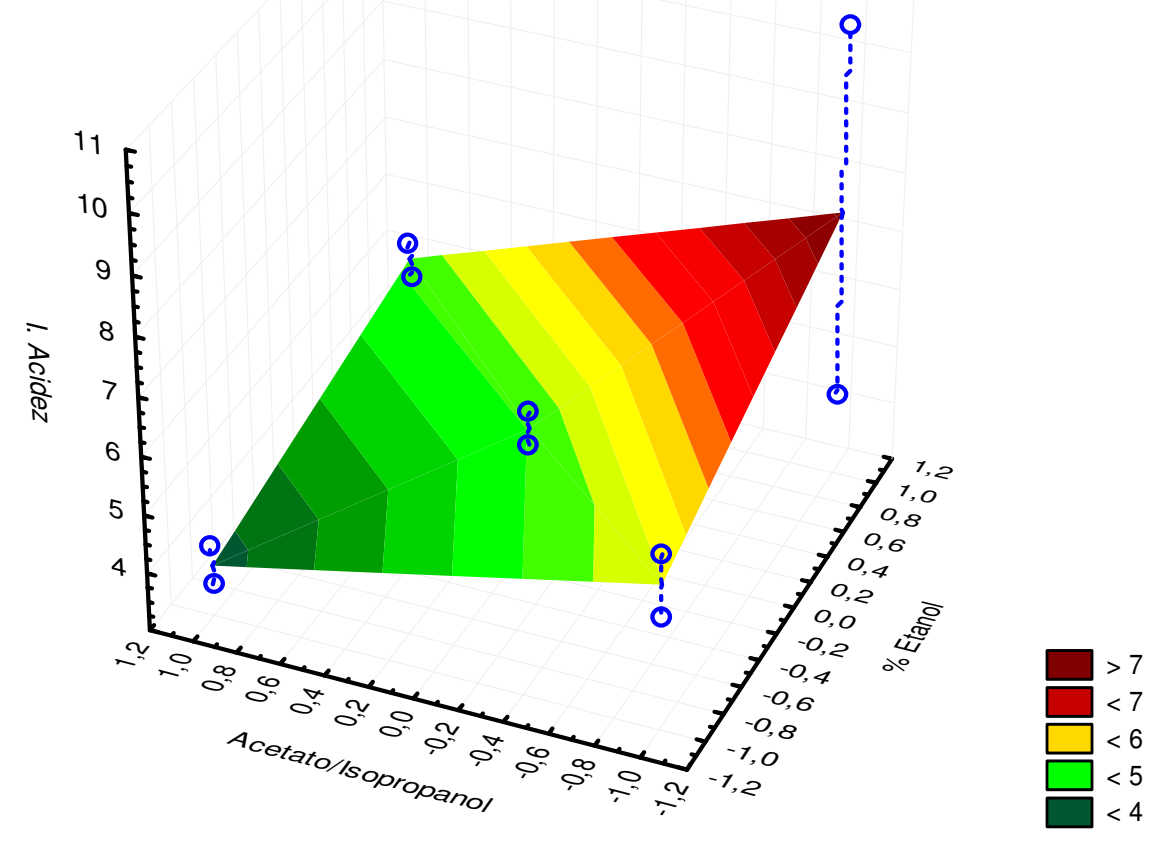

Figura 3 - Superfície de resposta para o índice de acidez. 


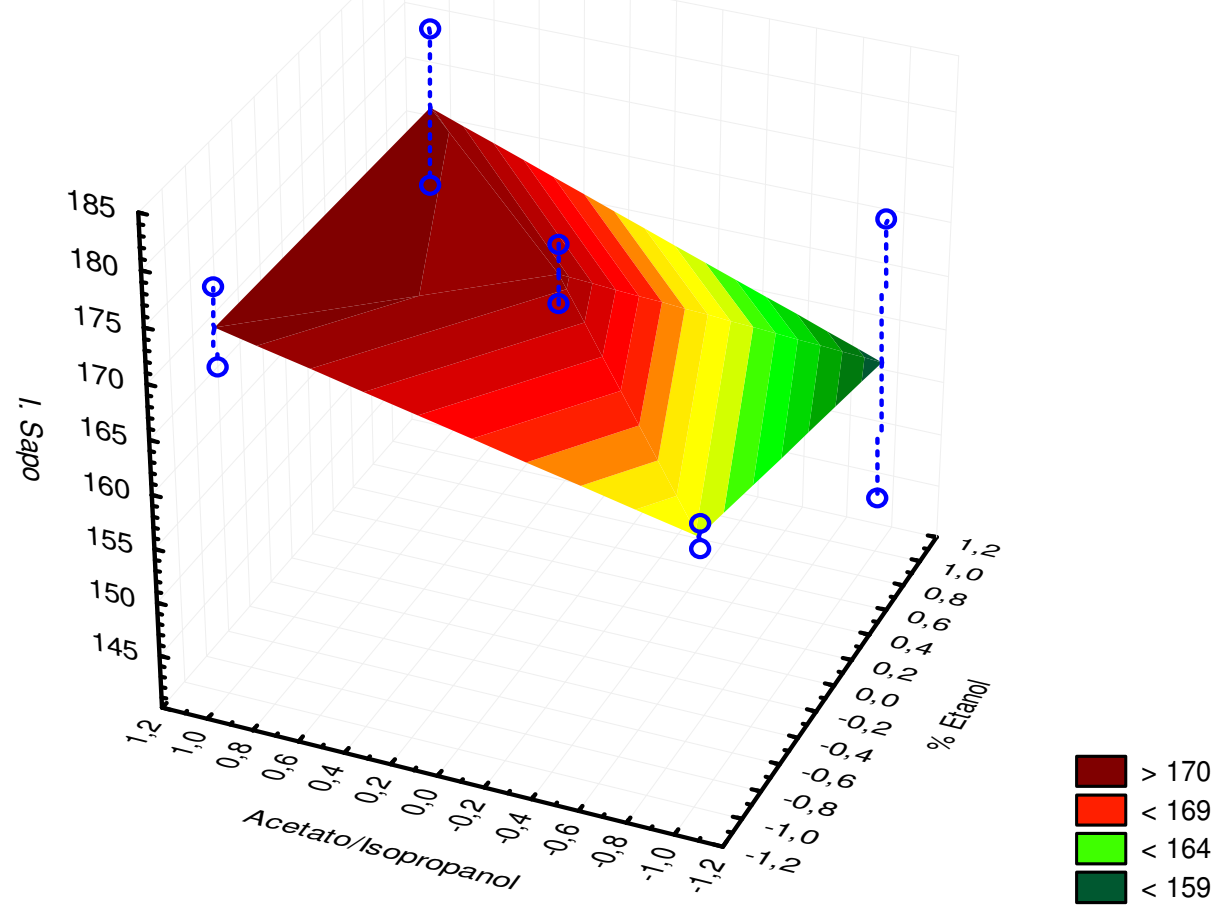

Figura 4 - Superfície de resposta para o índice de saponificação.

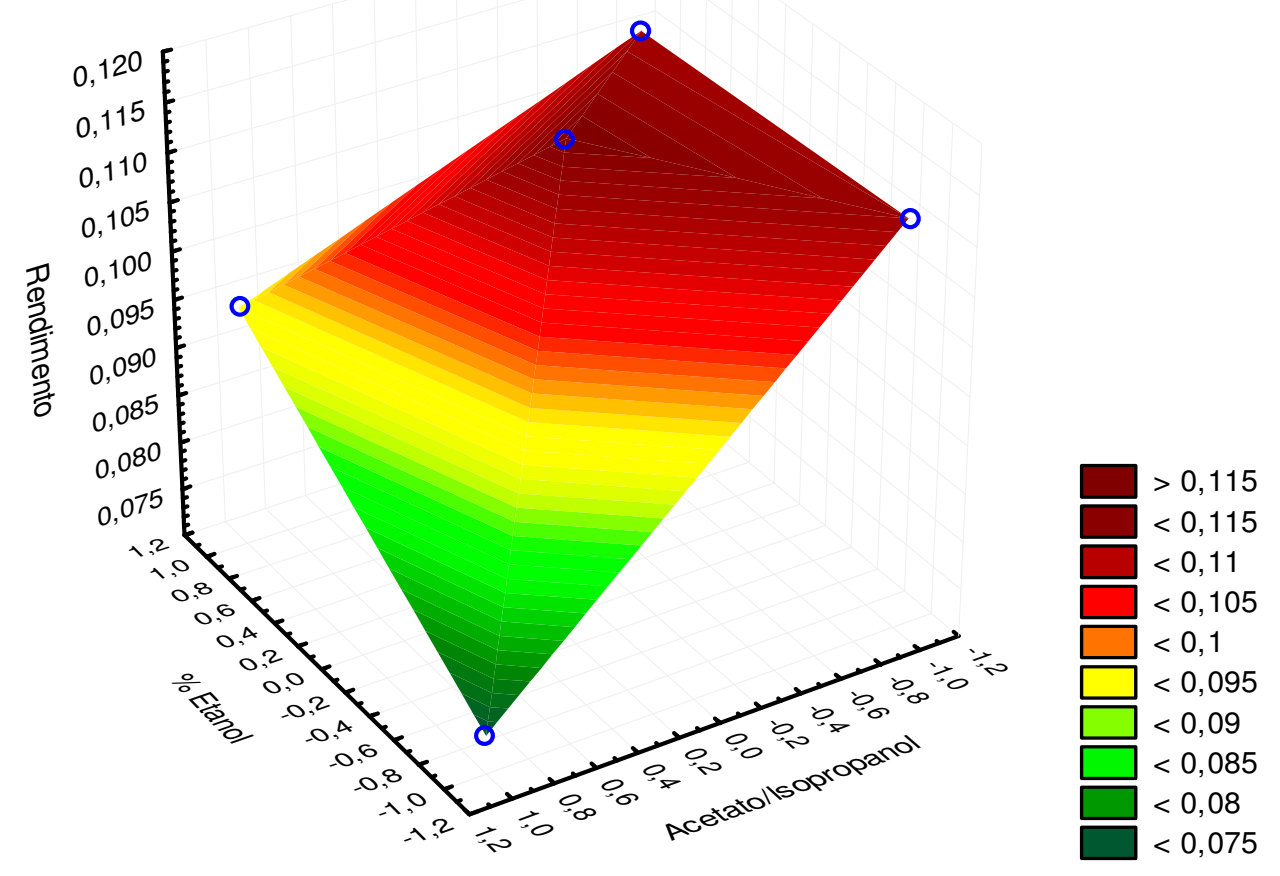

Figura 5 - Superfície de resposta para o rendimento da primeira batelada. 


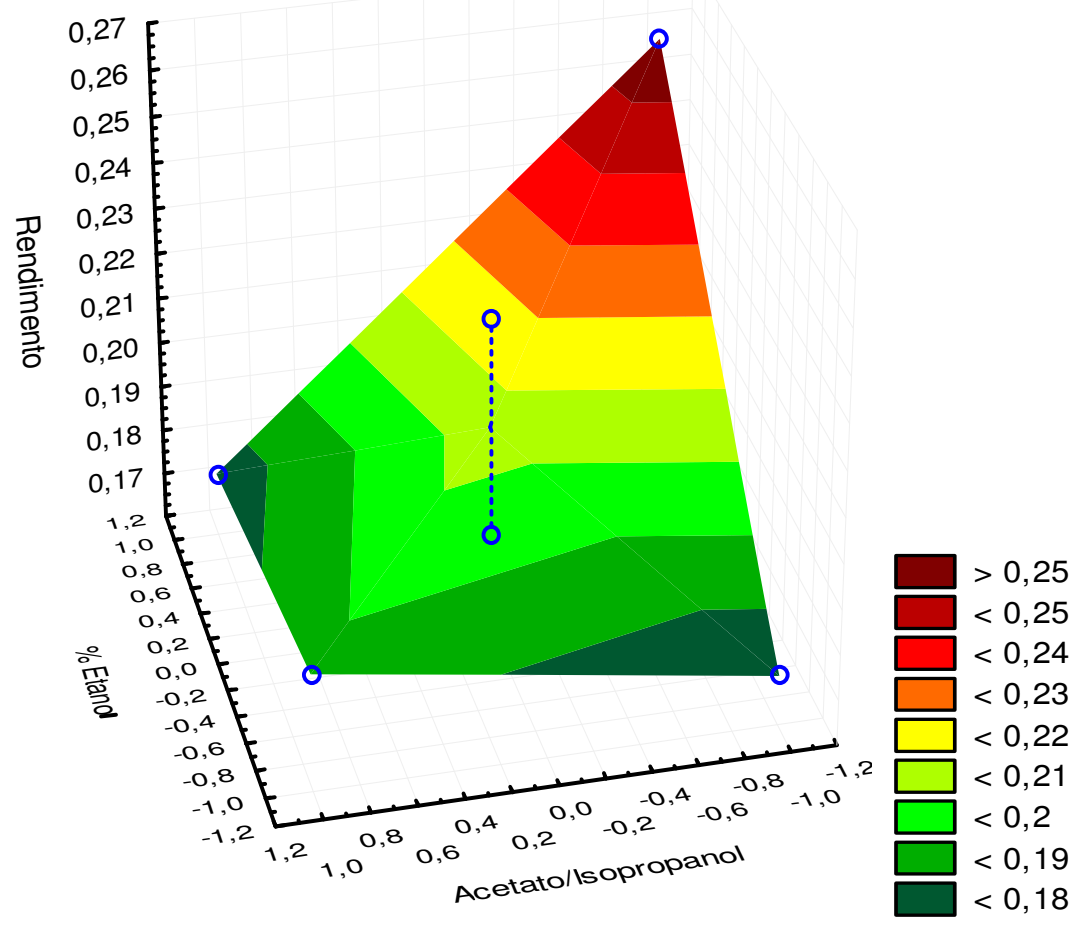

Figura 6 - Superfície de resposta para o rendimento da segunda batelada.

\subsection{Refino do Óleo Extraído com a Mistura Alternativa de Solvente}

Após as análises feitas através das caracterizações e do planejamento estatístico de experimentos visando o maior rendimento de óleo (óleo com resíduo), a mistura escolhida foi a 1, composta por $85 \%$ de etanol, $13 \%$ de isopropanol e $2 \%$ de acetato de etila, em frações mássicas. Uma nova extração com esta mistura de solventes foi realizada e obteve-se 110,05 $\mathrm{g}$ de óleo com resíduo que foi submetido ao processo de refino.

Paralelamente, homogeneizaram-se os óleos (sem os resíduos) remanescentes da primeira e segunda batelada, totalizando 95,42 g de óleo sem resíduo, também foram submetidos ao processo de refino, sendo identificado como "mistura de óleos".

Tanto a mistura de óleos residuais como o óleo bruto extraído na batelada adicional com a mistura de solventes 1 foram caracterizados segundo o índice de acidez antes do refino, apresentando valores de 7,5\% e 6,4\% em ácido oleico, respectivamente. Após o refino, o óleo da mistura 1 apresentou um índice de acidez de 0,7\%, um índice de saponificação de $154 \mathrm{mg} \mathrm{KOH} / \mathrm{g}$ e 1,4\% de umidade e matéria volátil. Já a mistura de óleo refinado apresentou valores $5,5 \%, 171 \mathrm{mg} \mathrm{KOH} / \mathrm{g}$ e 1,2\% para as respectivas características.

Entretanto, o refino dos óleos extraído a partir da mistura de solvente alternativo proposto neste trabalho ainda não está em conformidade com a especificação da ANVISA para óleos refinados (IA $<0,6 \%$, IS entre 189-195 mg KOH/g e U < 0,2 \%). Mas pode-se observar que o processo de refino foi mais eficaz para o óleo da mistura 1, onde o índice de acidez foi reduzido de $7,5 \%$ para $0,7 \%$, bastante próximo das especificações. 
Ao determinar a massa inicial e a massa final de óleo em cada etapa do refino foi possível calcular a perda de massa de óleo em cada do processo de refino, sendo representada por perdas em porcentagem na Tabela 7.

Tabela 7 - Massa de óleo retirada em cada etapa do refino.

\begin{tabular}{ccccc}
\hline \multirow{2}{*}{ Etapa } & \multicolumn{3}{c}{ Mistura 1 } & \multicolumn{2}{c}{ Mistura de óleos } \\
\cline { 2 - 5 } & Massa (g) & Perda de massa (\%) & Massa (g) & Perda de massa (\%) \\
\hline Extração & 110,05 & - & 95,420 & - \\
Degomagem & 68,341 & 37,900 & 81,990 & 14,075 \\
Neutralização & 42,477 & 37,846 & 62,939 & 23,236 \\
Braqueamento & 32,168 & 24,270 & 47,943 & 23,826 \\
Desodorização & 15,662 & - & 38,639 & 19,406 \\
\hline
\end{tabular}

Contudo, o óleo de maior rendimento na extração inicial não foi o de maior rendimento após o refino, sendo que as perdas para o óleo da mistura 1 somam cerca de $76 \%$ enquanto que para a mistura de óleos somam aproximadamente 60\%. Entretanto, vale lembrar que o óleo da mistura 1 foi submetido ao processo de refino juntamente com o seu resíduo, o qual foi removido na mistura de óleos remanescente.

Assim, pode-se afirmar que a presença do resíduo não é um problema para o processo de refino, apenas reduz o seu rendimento, uma vez que ele acaba sendo removido gradativamente em cada etapa do processo. Porém, a remoção do resíduo antes de submeter o óleo ao refino acarreta num menor consumo de reagentes e equipamentos menores.

Outra observação importante é que o processo de refino reproduzido em laboratório foi o processo de refino comumente utilizado no Brasil para óleos de soja, no qual a etapa de "winterization" não é realizada. Esta etapa geralmente precede o branqueamento tem o intuito de remover o ácido esteárico mediante resfriamento do óleo branqueado (SHEREV; BRINK, 1997). Desta forma, espera-se que esta etapa reduza ainda mais o índice de acidez e, consequentemente, aumente o índice de saponificação do óleo de soja extraído com a mistura alternativa de solventes, enquadrando-os nos índices estabelecidos pela ANVISA.

Finalmente, o refino utilizado para óleos brutos extraídos com hexano não foi eficiente para refinar óleos extraídos com a mistura alternativa de etanol, acetato de etila e isopropanol, sendo necessário um novo estudo para direcionar e adequar a etapa de refino.

\section{CONCLUSÃO}

O óleo extraído com hexano apresentou quase que na totalidade dos testes de caracterização, resultados dentro do estabelecido pela ANVISA, uma vez que, por não ter afinidade com água, o hexano extrai um óleo com baixo índice de acidez, sem odor e na ausência de resíduos além da extração ter sido realizada a uma temperatura inferior $\left(65^{\circ} \mathrm{C}\right)$, conforme o esperado.

Os óleos brutos obtidos com as misturas propostas foram analisados através dos índices de acidez e de saponificação, e pela umidade e matéria volátil, estando fora do estabelecido pela norma da ANVISA para óleos brutos, pois, o processo de hidrólise, devido a saponificação do óleo possivelmente ocorrido durante a extração, interferiu na qualidade do óleo extraído e nos resultados dos testes 
Apesar dos óleos extraídos com as misturas alternativas não serem óleos adequados segundo a ANVISA, algumas constatações foram interessantes: (1) os rendimentos das extrações com as misturas de solvente alternativas foram superiores à extração empregado hexano, o que é justificado pela extração de substâncias que possuem afinidade com o etanol e/ou acetato de etila e/ou isopropanol; (2) a formação de um resíduo no produto da extração, o qual precipita ao ser resfriado e/ou colocado em meio ausente desses solventes.

A afinidade do resíduo com as misturas de solventes torna desnecessário o resfriamento da micela e a separação do resíduo antes da destilação, contudo é interessante industrialmente em vista da dimensão e facilidade de operação dos destiladores.

A análise do polinômio ortogonal indica que a relação AcOEt/Isop é significante para os índices de acidez e saponificação, enquanto que o rendimento do processo de extração é independente das concentrações de solvente empregada, mas dependente se a etapa de destilação é realizada com ou sem o resíduo proveniente da extração.

A presença do resíduo não afetou qualitativamente o processo de refino, porém a sua remoção prévia resulta num menor consumidos de reagentes e, sendo as correntes menores, equipamentos em menores escalas acabam sendo necessários.

Finalmente, tanto os óleos brutos quanto os óleos refinados extraídos com a mistura alternativa de solventes não estão aptos para consumo humano, uma vez que os testes de índice de saponificação, umidade e matéria volátil não se enquadraram nas normas da ANVISA. Entretanto, o processo comum de refino reproduzido em laboratório foi possível reduzir bastante algumas características do óleo extraído na melhor condição indicada neste estudo, como o índice de acidez e umidade (7,5\% para $0,7 \%$ ácido oleico e de 3,5\% para $1,4 \%$, respectivamente), porém o refino não teve grande influência para o decaimento do índice de acidez para mistura de óleos (6,4\% ácido oleico passou a ter 5,5\% ácido oleico).

Visto que as características do óleo refinado extraído com a mistura de solvente alternativo estão próximas das condições exigidas pela ANIVSA e dada a existência de uma etapa extra (demargarinização) no processo de refino industrial para adequação das características do óleo de soja, um estudo do processo de refino do óleo de soja extraído com mistura de solvente alternativo, empregando da etapa de demargarinização, seria uma possibilidade de continuidade deste trabalho.

\section{AGRACIMENTOS}

Ao Centro Universitário FEI pelo suporte para o desenvolvimento do trabalho.

\section{REFERÊNCIAS}

AlmeidA, A.; CORAZZA, C.; ARAÚJO, C.; COSTA, E. Modelagem da Reação de Enxertia do Anidrido Maleico no Polipropileno Usando Moinho de Bolas como Reator Mecanoquímico. Trabalho de Conclusão de Curso. Centro Universitário da FEI. São Bernardo do Campo, 2014.

AMERICAN OIL CHEMISTS' SOCIETY. Official methods and recommended practices of the American Oil Chemists' Society. 4a ed. Champaign, USA. AOCS, 1990 
[AOCS Official method Cc 7-25].

ANVISA. Resolução RDC $\mathbf{n}^{\circ} 270$ de 22 de setembro de 2005. Emenda não oficial. Regulamento Técnico Para Óleos Vegetais, Gorduras Vegetais e Creme Vegetal. Disponível $\mathrm{em}$ : $<$ http://portal.anvisa.gov.br/wps/wcm/connect/82d8d2804ab68849647d64600696f00/ RDC_n_270.pdf?MOD=AJPERES>. Acesso em 18 ago. de 2015.

ASSOCIAÇÃO BRASILEIRA DE NORMAS TÉCNICAS. Determinação de Índice de Acidez. 2a ed. Rio de Janeiro, Brasil. ABNT, 2014 [Método Oficial ABNT NBR 11115:2014].

GAUTO, M. Química Industrial. Bookman. 1a ed. Porto Alegre. 2013.

IBGE. Levantamento Sistemático da Produção Agrícola. Confronto das Safras de 2014 e 2015 - Brasil. Disponível em: $<$ http://www.ibge.gov.br/home/estatistica/indicadores/agropecuaria/lspa/defaulttab.sht $\mathrm{m}>$. Acesso em 15 dez. de 2015.

INSTITUTO ADOLFO LUTZ. Normas Analíticas do Instituto Adolfo Lutz. v.1: Métodos Químicos e Físicos para Análise de Alimentos. $3^{a}$ ed. São Paulo. 1985.

NETO, B; SCARMINIO, I.; BRUNS, R. Como Fazer Experimentos. $4^{\mathrm{a}}$ ed. Bookman, 2010.

NOVAZZI, L. F.; HIPÓLITO, F. C. Estudo da Transferência de Massa na Extração de Óleos Vegetais com Solvente em Extrator Soxhlet. XIX Congresso Brasileiro de Engenharia Química (COBEQ). Rio de Janeiro. 2012.

PARAÍSO, P. R. Modelagem e Análise do Processo de Obtenção do Óleo de Soja. Tese de doutorado. Faculdade de Engenharia Química. Universidade Estadual de Campinas. Campinas. 2001.

RODRIGUES, C. E. C. Utilização de Solvente Biorenovável Nos Processos de Extração e Desacidificação de Óleos Vegetais. Tese - Livre docência. Faculdade de Zootecnia e Engenharia de Alimentos. Universidade de São Paulo. Pirassununga. 2011.

RODRIGUES, M.; IEMMA, A. Planejamento de Experimentos e Otimização de Processos. Campinas, Brasil. Casa do Pão, 2005.

SHEREV, R. N.; BRINK Jr., J. A. Indústrias de Processos Químicos. $4^{\mathrm{a}}$ ed. Grupo GEN, 1997. 


\title{
STUDY OF ALTERNATIVE SOLVENT USE IN THE SOYBEAN OIL PROCESS
}

\author{
D. B. BAIÃO ${ }^{1}$, B. S. GARÉ ${ }^{1}$, A. C. M. RIBEIRO ${ }^{1}$, N. G. TROVÃO ${ }^{1}$, R. CONDOTTA ${ }^{1, *}$ \\ ${ }^{1}$ FEI University, Department of Chemical Engineering \\ "E-mail: rcondotta@fei.edu.br
}

\begin{abstract}
The extraction of soybean oil is made almost exclusively by the solvent extraction method, which uses the commercial hexane. In order to evaluate new solvents as an alternative to the traditional extraction process, an study of soybean oil extraction process using mixtures of ethanol, ethyl acetate and isopropanol as solvent were carried out. As results, the best extraction yield was obtained by the mixture containing $85 \%$ of ethanol, $13 \%$ of isopropanol and $2 \%$ of ethyl acetate (0,185g oil/g of soybean). Despite of the obtained oil presents the acidity and saponification index divergent from ANVISA's specification for crude soybean oil, the refinement of this oil has improved some of its properties, such as the acid index: $0,7 \%$ of oleic acid (specified $<0,6 \%$ ). The winterization step on refining process could improve of some other soybean oil properties obtained using the alternative solvent mixture proposed.
\end{abstract}

KEYWORDS: Soybean oil; Extraction; Solvent; Refining. 